\title{
Flexible platforms for natural orifice transluminal and endoluminal surgery
}

Authors

Institutions
Nisha Patel ${ }^{1,2}$, Carlo Seneci ${ }^{2}$, Guang-Zhong Yang ${ }^{2}$, Ara Darzi ${ }^{1,2}$, Julian Teare ${ }^{1,2}$

1 St. Mary's Hospital, Imperial - Gastroenterology, London, United Kingdom

${ }^{2}$ Hamlyn Centre - Robotics and Engineering, London, United Kingdom
Bibliography

DOI http://dx.doi.org/

10.1055/s-0034-1377171

Published online: 6.6.2014

Endoscopy International Open

2014; 02: E117-E123

(c) Georg Thieme Verlag KG

Stuttgart · New York

E-ISSN 2196-9736

\section{Corresponding author}

Nisha Patel, BSc (Hons), MBBS

(Hons), MRCP

St. Mary's Hospital -

Gastroenterology

Praed St, Paddington, London

W2 1NY

United Kingdom

Phone: 07971679313

Fax: 07971679313

nishakpatel1@gmail.com
The flexible endoscope is playing an increasingly pivotal role in minimally invasive transluminal and endoluminal surgery. Whilst the flexible nature of the platform is desirable in order to navigate through the abdominal cavity or through a lumen, there are a number of issues with using the platform for this purpose.

The challenges associated with using flexible endoscopes such as a lack of triangulation of instruments and force transmission, which is often inadequate for endoscopic surgery are discussed in this review.

\section{Introduction}

The evolution of the flexible endoscope is transforming both gastroenterology and surgery. Since Bozzini first used candlelight to examine "canals and cavities of the human body" [1], the endoscope has undergone repeated improvements. Modifications to the basic design in the $1960 \mathrm{~s}$ improved the image quality, although few changes have occurred since.

Laparoscopic surgery marked the dawn of minimally invasive surgery, prompting the advent of other techniques, such as natural orifice transluminal endoscopic surgery (NOTES) and endoluminal surgery (ELS). This new surgical philosophy places an emphasis on minimizing trauma with smaller or no incisions, thereby resulting in less soft tissue damage. Other benefits include improved cosmesis, faster recovery times, fewer complications, and less postoperative pain. This paradigm shift has placed the flexible endoscope at the forefront of a range of clinical scenarios. Despite considerable evolutions in the field of surgery, the basic design of the flexible endoscope has changed little since its initial development. However, this is likely to change with the growing popularity of ELS and the goal to integrate NOTES into clinical practice. The device has been modi-
As a result of these difficulties, a number of mechanically and robotically driven devices based upon the flexible endoscope are emerging. The design of these devices and potential problems are also reviewed. Finally, future robotic systems which are still in the development and validation stage are briefly discussed.

The field of gastroenterology is diverging. The narrowing divide between minimally invasive and endoluminal surgery has led to a surge of innovative and novel devices which may in the future enable precise, seamless and scar less surgery.

fied over the years, becoming slimmer, offering variable degrees of stiffness and advanced imaging, and revolutionizing the field of gastroenterology. Nonetheless, barriers to NOTES, such as reliable and safe internal wound closure, access to the peritoneal cavity, visualization, and spatial orientation, remain and hinder its wider uptake [2]. NOSCAR (Natural Orifice Surgery Consortium for Assessment and Research), the working group of the American Society of Gastrointestinal Endoscopy (ASGE)/Society of American Gastrointestinal and Endoscopic Surgeons (SAGES), published its white paper in 2006 [3], leading to a number of emerging platforms for NOTES and ELS.

Limitations of and improvements to all devices have been described, and as yet there is no clear superior platform. While flexible platforms allow navigation and surgery in tight workspaces, they often fail to achieve the desired forces at the distal tip effectors for adequate tissue handling and dissection [2]. In addition, there is often a lack of stability and dexterity, inadequate positioning of the scope, and a lack of triangulation of instruments down the working channel of a scope with a narrowed diameter $(\checkmark$ Table $\mathbf{1})$.

An exciting endeavor in the development of a workable NOTES and ELS platform is robotics. 
Table 1 Limitations of the flexible endoscope.

Number of therapeutic channels
Size of therapeutic channels
Inadequate suctioning/irrigation capabilities
Unregulated insufflators
Not a multitasking platform
Inability to adequately stiffen/fix the platform to improve stability and
tissue exposure
Fixed visual horizon
Limited views of endoscope
Inadequate triangulation of instruments
Lack of force transmission at distal instrument tip
Inadequate tissue retraction, tissue traction, and tissue countertraction
due to flexibility
Spatial disorientation, particularly during retroflexion
Lack of smooth, controlled distal tip movements for precise dissection

This field has undergone a revolution since the introduction of robots such as the Da Vinci, with a drive to miniaturize robots and operate in an intraluminal workspace.

A number of robots are in development or are being used for a wide range of roles ranging from aviation and aerospace to security and nuclear technology, yet design iterations for a robotic minimally invasive surgical platform remain. Robots like the Flex System (Medrobotics, Raynham, MA, USA) and the highly articulated robotic probe (HARP) have been designed for surgery in difficult-to-reach anatomic areas, such as the oropharynx and heart. The Endotics system (Era Endoscopy, Peccioli, Italy) [4] and the soft colonoscopy robotic platform developed by engineers at Vanderbilt University in Nashville, Tennessee, United States, are exciting new prospects for robotic colonoscopy $[5,6]$ in which semi-automatic inchworm motion and magnetic coupling, respectively, are used. Emerging robots from Intuitive Surgical (Sunnyvale, CA, USA) and Titan Medical Inc. (Toronto, ON, Canada) with highly dextrous micro-instruments may also be potential future platforms for endoluminal and transluminal surgery.

The flexible endoscopic platform plays a key role in NOTES and ELS; however, challenges remain. This review focuses on emerging flexible platforms that are being developed for NOTES and ELS.Although these devices are not yet commercially available, they incorporate changes to the long-standing basic design of the endoscope that provide a more versatile platform for ELS.

\section{Nonrobotic endoscopic platforms}

Endoscopic platforms for NOTES and ELS are largely adapted from the flexible endoscope ( Table 2, Fig. 1). Although this allows a flexible platform to operate in a restricted workspace, optimal visualization of the mucosa and tissue manipulation remain problematic.

Dual-channel endoscope (Olympus, Hamburg, Germany) The dual-channel endoscope was developed to improve bimanual coordination and tissue manipulation compared with a conventional endoscope. The endoscope consists of a control section with two stacked control dials, a flexible shaft, and a connector segment. The connector segment attaches to water, a light source, an image processor, and air or carbon dioxide for insufflation. It requires one operator to use the device, although an assistant is often needed to operate the instruments.

The device has a $120^{\circ}$ field of view with four-way angulation and a flexible shaft that is $12.6 \mathrm{~mm}$ in diameter housing a $3.7-\mathrm{mm}$ channel for suctioning and a $2.8-\mathrm{mm}$ working channel. This enables the use of two interchangeable instruments, including focused energy devices, to be deployed simultaneously. Early NOTES procedures and hybrid NOTES/laparoscopic procedures were performed with this device $[7,8]$.

Bimanual coordination for adequate tissue manipulation and dissection is almost impossible; a hybrid approach improves the ability to retract tissue. This is in part due to the fact the working channels are placed parallel and adjacent to the camera. The camera is at the distal tip of the scope, so that the instrument must be retracted to provide a view of the operative field. Insufflation of the peritoneal cavity also requires a supplemental force, and often large-volume suction capabilities are inadequate.

\section{EndoSamurai (Olympus)}

The EndoSamurai is a multitasking flexible endoscopic platform developed for NOTES procedures. It is an endoscopic shaft with two independent manipulator arms containing working channels through which flexible instruments can be interchangeably operated. The arms remain parallel to the shaft during insertion and can be opened out into the working position, giving the appearance of elbows. This stance allows five degrees of freedom and better triangulation of instruments than is achievable with

Table 2 Mechanical multitasking platforms. N/A- not available.

\begin{tabular}{|c|c|c|c|c|c|c|c|}
\hline Name & $\begin{array}{l}\text { Outer } \\
\text { diameter, } \\
\text { mm }\end{array}$ & $\begin{array}{l}\text { Length, } \\
\mathrm{cm}\end{array}$ & $\begin{array}{l}\text { No. of } \\
\text { instrument } \\
\text { channels }\end{array}$ & $\begin{array}{l}\text { Optics: inte- } \\
\text { grated }(\mathrm{I}) \text { or } \\
\text { insertable ( } \mathrm{N})\end{array}$ & $\begin{array}{l}\text { Overtube/over- } \\
\text { sheath required? }\end{array}$ & $\begin{array}{l}\text { Commercially } \\
\text { available? }\end{array}$ & $\begin{array}{l}\text { Ex vivo and in vivo } \\
\text { animal }(A), \text { cadaver }(C) \text {, } \\
\text { and human }(H) \text { studies }\end{array}$ \\
\hline $\begin{array}{l}\text { Dual-channel } \\
\text { endoscope }\end{array}$ & 12.6 & 103 & 2 & 1 & No & Yes & A, $\mathrm{H}$ \\
\hline EndoSamurai & $\begin{array}{l}18 \text { (with } \\
\text { overtube) }\end{array}$ & 103 & 3 & 1 & Yes & Yes & $\mathrm{A}, \mathrm{H}$ \\
\hline ANUBIScope & 16 & 110 & 3 & 1 & No & Yes & $A, C$ \\
\hline R-Scope & 14.3 & 133 & 2 & 1 & No & Yes & A, $\mathrm{H}$ \\
\hline IOP & 18 & 110 & 4 & $\mathrm{~N}$ & Yes & Yes & $\mathrm{A}, \mathrm{C}, \mathrm{H}$ \\
\hline Cobra & $\mathrm{N} / \mathrm{A}$ & $\mathrm{N} / \mathrm{A}$ & 3 & $\mathrm{~N}$ & Yes & No & A \\
\hline DDES & $16 / 22$ & 55 & 3 & $\mathrm{~N}$ & Yes & Yes & $A$ \\
\hline
\end{tabular}

DDES, Direct Drive Endoscopic System; IOP, Incisionless Operating Platform; N/A, not available. 

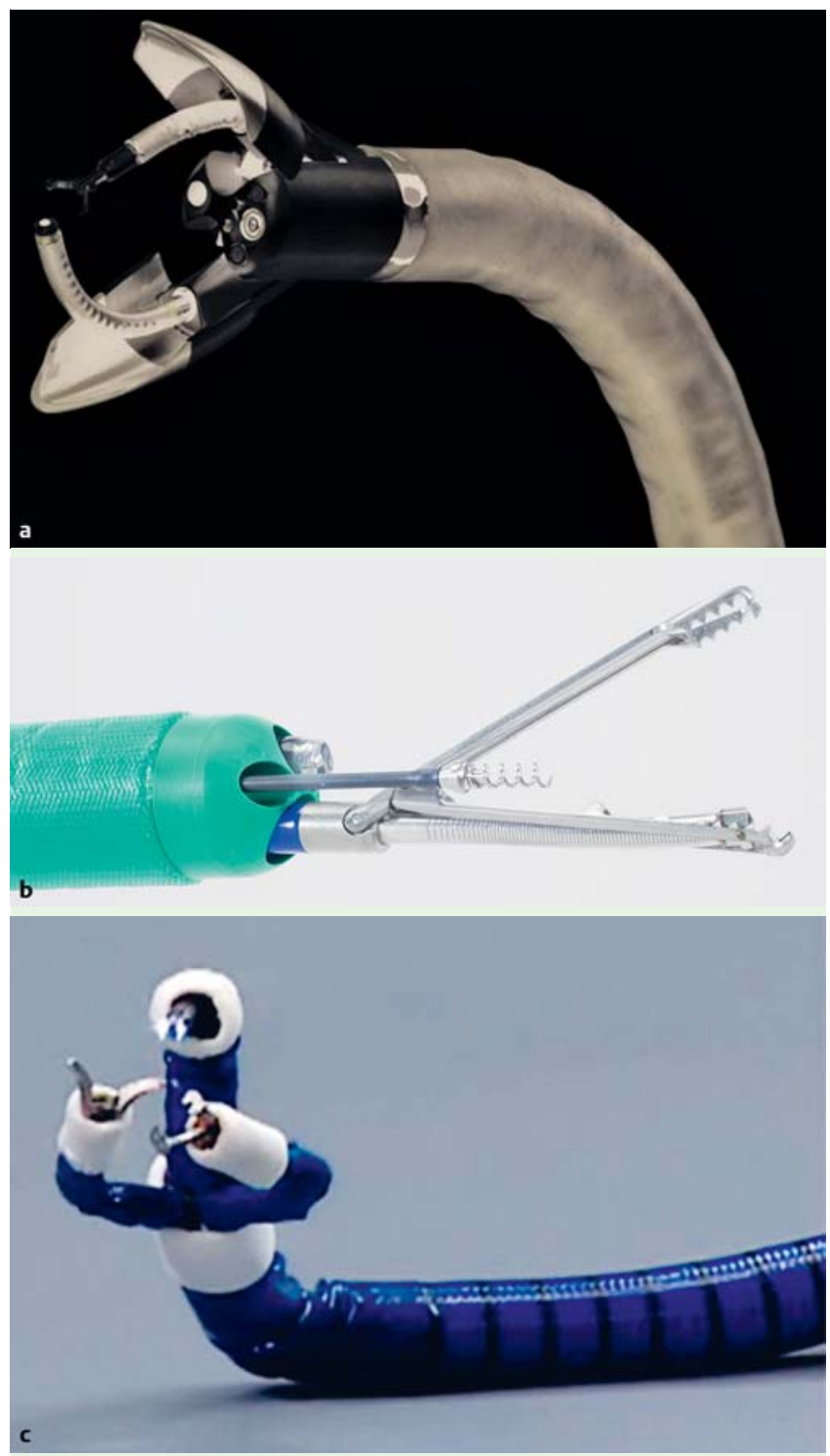

Fig. 1 Mechanical multitasking platforms. a ANUBIScope; b TransPort; c Cobra.

a dual-channel endoscope. A third working channel is also included in the shaft, although its position does not allow adequate triangulation of instruments and hence provides suboptimal countertraction of tissue.

The platform uses a traditional endoscopic steering unit with conventional endoscopic features, such as suction, lens rinsing, and air insufflation. An overtube allows stable positioning of the device once it is locked into place. The arms can then be manipulated with an ergonomic interface comprising laparoscope-like handles in a "drive, park, and move" fashion. Although the overtube improves stability of the platform, it requires repeated adjustments, thus increasing procedural time.

Overall, this is an improved platform for NOTES and endoluminal surgery that allows better triangulation of instruments, stability, and manipulation of tissue than does a dual-channel endoscope [9]. It has been tested in both bench top and in vivo animal studies in the performance of transgastric small-bowel resection and intra-abdominal exploration [10]. Aspects for which potential improvements should be be considered include the complex control, which causes a delay in the end effectors, and the retroflex- ion capabilities; in addition, the optics are housed in the shaft, creating inadequate visualization as a result of the long distance between the instruments and lens. Accurate dissection with one arm of the device while larger organs, such as bowel, are retracted can be difficult because of inadequate mobility.

\section{ANUBIScope (Karl Storz, Tuttlingen, Germany)}

Storz and IRCAD (Institut de Recherche contre les Cancers de l'Appareil Digestif)) collaborated in the ANUBIS project [11] to develop this reusable flexible platform in 2005. A four-way articulating flexible endoscopic shaft, $16 \mathrm{~mm}$ in diameter, provides endoscope-style navigation and maneuverability. The $18-\mathrm{mm}$ articulating distal tip has a novel tulip shape comprising two wings that remain closed during entry, acting as a blunt trocar to prevent injury. The wings, with a $4.2-\mathrm{mm}$ working channel in each, open in the working configuration, allowing two opposing arms to emerge. This distal configuration enables the triangulation of up to three articulated instruments, although the wings limit the maneuverability of the device in confined spaces, such as a lumen. A further 3.4-mm central channel is located in the shaft. Control of the arms is achieved by manipulation of the introduced tools down the working channels, enabling faster working times in the absence of a control interface. A number of animal and cadaveric studies have been performed. Successful procedures include distal pancreatectomy [12], sigmoidectomy [13], and transgastric cholecystectomy $[14,15]$. The first successful transvaginal cholecystectomy with the device, performed in 60 minutes, was recently published [16].

These studies have highlighted some limitations, including difficulties with gastrotomy closure and with spatial orientation and retraction when the instrument is in a retroflexed position. Visualization is affected by the integrated optics, and stability of the platform is achieved by fixation to a stand. Improvements to create an articulated device with adequate triangulation of instruments and stability, allowing the resection of lesions in retroflexion and in awkward configurations, could be made.

\section{R-Scope (Olympus)}

This 13.5-mm-diameter flexible dual-channel endoscope was developed by Olympus for endoscopic submucosal dissection $[17,18]$, but it has potential for NOTES and other ELS procedures. It addresses common challenges posed by the dual-channel endoscope, including triangulation of instruments, positioning, and stability. Earlier prototypes had multibending, separately controllable segments [19]; although an advance on the M-scope (Olympus), this feature is not present on the current model as difficulties arose during retroflexion and it was felt that it added little to the maneuvering ability.

There are two articulated 2.8-mm working channels with horizontal and vertical lifting gates, positioned $90^{\circ}$ to each other. This configuration allows simultaneous but separate movements of instruments in perpendicular planes, improving the accuracy of off-axis movements during tissue dissection.

The platform has been used to perform a number of procedures, including transgastric cholecystectomy [20], distal pancreatectomy [21], and endoscopic submucosal dissection [22]. The platform improves traction and countertraction of tissue in in vivo studies [23] and has been shown to reduce gastric endoscopic submucosal dissection procedural time [22]. However, bimanual coordination without the aid of a laparoscopic port - for example, for liver retraction during cholecystectomy - can be difficult. 
Table 3 Robotic platforms.

\begin{tabular}{|c|c|c|c|c|c|c|c|}
\hline Name & $\begin{array}{l}\text { No. of } \\
\text { operators }\end{array}$ & Triangulation? & $\begin{array}{l}\text { Integrated } \\
\text { optics }\end{array}$ & $\begin{array}{l}\text { Degrees of } \\
\text { freedom, total }\end{array}$ & $\begin{array}{l}\text { Interchangeable } \\
\text { instruments/end } \\
\text { effectors }\end{array}$ & $\begin{array}{l}\text { Commercially } \\
\text { available? }\end{array}$ & $\begin{array}{l}\text { Ex vivo and in vivo ani- } \\
\text { mal }(A) \text {, cadaver }(C), \\
\text { and human }(H) \text { studies }\end{array}$ \\
\hline NeoGuide & 2 & No & Yes & $\begin{array}{l}32 \text { ( } 16 \text { segments, } \\
\text { each with } 2 \text { de- } \\
\text { grees of freedom) }\end{array}$ & Yes & Yes & $\mathrm{A}, \mathrm{H}$ \\
\hline MASTER & 2 & Yes & Yes & 9 & No & No & $\mathrm{A}, \mathrm{H}$ \\
\hline $\begin{array}{l}\text { Master-slave trans- } \\
\text { luminal endo- } \\
\text { scopic robot }\end{array}$ & 1 & Yes & Yes & $\begin{array}{l}6 \text { positioning and } \\
\text { sheath, } \\
8 \text { end effectors }\end{array}$ & Yes & No & A \\
\hline ViaCath & 1 & Yes & Yes & $6+$ grip & Yes & No & A \\
\hline i-Snake & 1 & Yes & Yes & 8 & Yes & No & A \\
\hline
\end{tabular}

Although the R-Scope is an improvement on the dual-channel endoscope, further improvements to the stability of the device, ability to perform precise dissection, and degrees of freedom of the platform $[23,24]$ are required. Furthermore, the operator can easily become disorientated when the instrument is in the retroflexed position; the field of view can be limited, and coordination of the platform remains problematic.

\section{Incisionless operating platform (USGI Medical, San Clemente, CA, USA)}

This flexible multilumen platform consists of the multitasking TransPort device and tools for tissue approximation, manipulation, and suturing. The TransPort device is a flexible, steerable oversheath, $18 \mathrm{~mm}$ in diameter, with conventional endoscopic control mechanisms. Four working channels (7, 6, 4, and $4 \mathrm{~mm}$ ) allow a variety of instruments to be used interchangeably, enabling tissue manipulation and resection. Visualization is achieved by inserting a flexible endoscope, such as an N-scope (Olympus), into the 6-mm channel and irrigation down another channel. Four-way flexibility of the distal tip allows fine precision control, enhanced deflection, and adjustable visual horizon control.

The ShapeLock function of the oversheath of this ergonomic platform, which improves stability, is a novel feature of the device. A series of titanium rings allows the flexible shaft to be stiffened once in position, improving the stability [25], lifting strength, and torsion abilities compared with a conventional endoscope [26].

The device has been tested extensively in animals and humans; the first transgastric cholecystectomy was performed in 2007. Gastric fundoplication, diaphragmatic hernia repair, and hybrid laparoscopic/NOTES procedures in humans, such as transgastric and transvaginal cholecystectomies, have been performed [2730]. These encouraging studies have highlighted some needed improvements to the platform; rectification could significantly enhance its performance.

A lack of integrated optics in the device means that the optics are housed in one of the four working channels; the arrangement of the working channels may limit the effective working space, and smooth, precise control of the distal tip can be difficult. Skilled operators and assistants are required for scope navigation, positioning, and orientation and for instrument exchange, rendering this a stable but challenging platform.

The USGI Cobra device was designed to address the difficulties in the triangulation of instruments encountered with the TransPort device. A 6-mm flexible endoscope could be passed through the center of the device, and shape-lock technology enabled locking of the device once in place. Two arms enabled tissue manipulation; however, the whole platform had to be removed in order to exchange tools [31]. Precise dissection was also problematic because of imprecise cable-driven controls, and ultimately this device was abandoned in 2012.

\section{Direct Drive Endoscopic System (Boston Scientific, Natick, MA, USA)}

This platform consists of a flexible controllable sheath steered with conventional endoscopic controls, a mobile rail system that can fix the platform directly to the operating table, and 4-mm articulated flexible controllable instruments [32].

Three working channels are housed within the sheath that allow passage of a small $(<6 \mathrm{~mm})$ endoscope, providing independent flexible optics down a 6-mm channel. There are also two 4-mm multidirectional tendon-driven instruments that contribute to the seven degrees of freedom of motion the platform allows (two at the shaft and five at the distal instrument tip). Their working length can extend to $12 \mathrm{~cm}$ beyond the distal end of the sheath and are controlled by two ergonomic handles.

Although the platform has been successfully used in animal studies, its translation to human studies will require further modification of the platform. It was shown to be superior to both the dual-channel endoscope and R-Scope with respect to bench top experiments, reducing procedural time and improving bimanual coordination $[33,34]$. However, a shaft length of $55 \mathrm{~cm}$ in total limits procedures in certain areas, such as the proximal colon and beyond the stomach.

If this system is to be a platform that has multiprocedural capabilities, changes to the sheath to improve torque need to be made. Difficulties with the parallel orientation of the forceps, interfering with the optical axis, and repeated recalibrations to the rail system also require correction to decrease disturbances during procedures. Furthermore, despite the platform-specific instruments that improve triangulation and tissue dissection, only a limited number of types are available.

\section{Robotic platforms}

$\nabla$

A summary of robotic platforms appears in Table 3 . The snakelike model is preferred for natural orifice "scarless" surgery to be achieved ( Fig. 2). A number of emerging robots are in the research phase of development that could have a role in endoluminal surgery. Current devices developed for endoluminal procedures require modification of their design to accommodate the restrictive workspace. Simaan and colleagues have developed a 

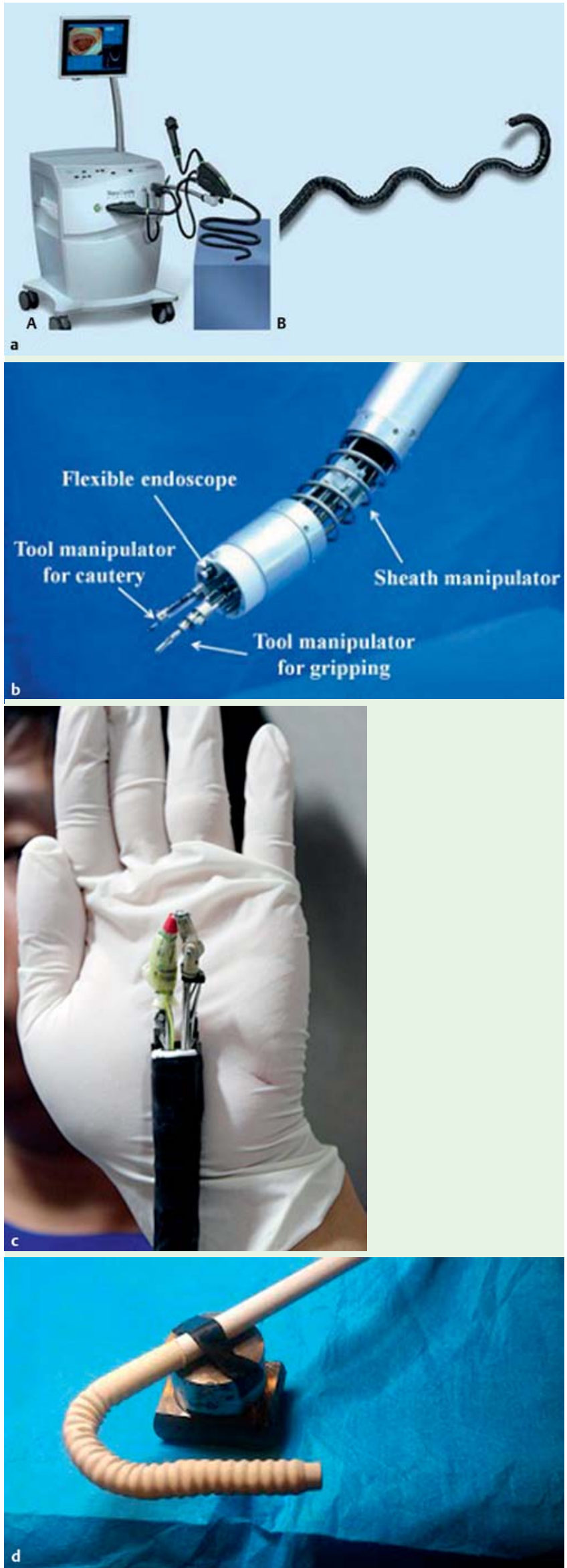

Fig. 2 Robotic interface platforms. a NeoGuide; b Master-slave system (IRCAD); c MASTER; d i-Snake. tele-robotic system for deep access to tight workspaces, such as the oropharynx [35]. This dual-arm slave robot has actuated distal dexterity units that are able to transmit rotation along their backbones, allowing movement in 20 degrees of freedom. This has potential for application in myriad procedures, including endoluminal surgery, neurosurgery, and fetal surgery.

Another promising robot for endoluminal surgery is a four-jointed snakelike robot developed by Choset and colleagues. Each joint enables movement in three degrees of freedom, allowing 12 degrees of freedom of movement in total. In addition, each joint can produce $5 \mathrm{Nm}$ of torque, a highly desirable feature [36]. One of the most exciting ventures is the "array of robots augmenting the kinematics of endoluminal surgery" (ARAKNES) project [37]. This team has endeavored to develop a micro-robot-based operating system to advance minimally invasive surgery. Bimanual tele-operated robots equipped with micro-robotic instruments equivalent to those of laparoscopic surgical robots can perform surgery for conditions such as obesity and gastroesophageal reflux disease.

\section{NeoGuide Endoscopy System (Intuitive Surgical, Sunnyvale, CA, USA)}

This is a novel computer-assisted colonoscope that provides realtime three-dimensional mapping of the colonoscope to reduce looping and pain during colonoscopy. The flexible shaft consists of 16 segments, each measuring $8 \mathrm{~cm}$, that allow automatic shape control of the shaft. During manual insertion, the position and angle of the distal, leading segment tip are encoded in a computer algorithm with position sensors. This results in articulation of the shaft based on mapping of the tip configuration during insertion. The subsequent 15 coupled segments then follow in a "follow-the-leader" fashion. As a result, the operator has a luminal view of the colon as well as a simultaneous image of the tip position and insertional tube shape.

Bench top studies of colonic models have shown a reduction of lateral forces and a reduction in looping compared with conventional colonoscopes [38]. A study has also shown that the NeoGuide provides accurate information regarding looping, tip position, and insertional tube position [39]. A feasibility study has shown it to be an effective and safe platform, with successful navigation to the cecum in 10 patients [40]. In addition, this study showed physician and patient satisfaction with the platform. Although this is a single-operator platform, all the procedures were performed by two operators: one to inserted the tube manually and another to steer the platform.

This is a promising flexible prototype with the potential to perform complex endoluminal procedures. Further larger-scale human studies are now warranted to improve it.

\section{Master-slave system for NOTES (IRCAD, Strasbourg, France)}

This master-slave tele-operated robot was designed in collaboration with Karl Storz. The slave component has two hollow, flexible, snakelike, tendon-driven arms through which instruments can be inserted and operated, providing movement in two degrees of freedom [41]. The slave component is attached to the distal tip of an endoscope with a specially designed cap to provide triangulation of the instruments by deflection of the arms away from the scope axis. Rotation and translation of passive movements can be decoupled and controlled separately.

The master console is a desklike workstation, and the system can provide up to 12 degrees of freedom in total. The main drawback 
of this robot is that the attachments are large and cumbersome; a carrying cart is needed to hold the slave arms and motorized endoscope in place.

\section{ViaCath robot (Hansen Medical, Mountain View, CA, USA)}

This robot, developed by EndoVia Medical (now Hansen Medical) [42], consists of an ergonomically designed master control system and haptic interface mechanisms within a desk-workstation design. Thumb control buttons on the master control handles allow a swift change of instruments and system settings, and they fix the platform into place. The slave system consists of an articulated overtube that is able to introduce a flexible endoscope and two highly articulated instruments with six degrees of freedom. ViaCath flexible instruments are $90 \mathrm{~cm}$ long with an articulating end effector tip. The distal tip has a double flex section, allowing an $S$ curve to be generated for accurate orientation of the custommade end effectors, which include graspers, electrocautery knives, and needle holders.

Improvements to the instruments and overtube are in development to overcome problems experienced during intubation of the patient and instrument positioning, and to increase the force generated at the distal instrument tip for adequate tissue manipulation.

\section{MASTER (Nanyang University, Singapore)}

The master and slave transluminal endoscopic robot (MASTER) was developed by Phee and colleagues in Singapore $[43,44]$. The robot consists of a tele-surgical workstation, a master console, and a flexible slave manipulator. The slave component has two motor-driven end effectors (a grasper and a monopolar electrocautery hook) mounted on the tip of two actuated arms attached to a conventional endoscope [45]. This allows movement in seven degrees of freedom by tendon activation and in two by direct drive. The system has been used to perform in vivo NOTES procedures, including cholecystectomy, liver resections [46], and gastric endoscopic submucosal dissection $[47,48]$.

Despite these encouraging studies, difficulties with the platform remain. Friction in the tendon sheath causes a delay in the operation of the master controller, inhibiting seamless surgery. The end effectors are fixed, so that surgery is limited to the use of these instruments and insertion also requires an overtube. Precision of the arms is compromised by retroflexion of the scope, and furthermore, questions regarding the sterilization process and gastrotomy closure remain unanswered, hindering its use.

\section{i-Snake (Hamlyn Centre, Imperial College, London, United Kingdom)}

This multiarticulated bio-inspired snake robot is $150 \mathrm{~mm}$ long and $12.7 \mathrm{~mm}$ in diameter, with a $50-\mathrm{mm}$ semirigid neck. It is based upon a universal joint mechanism with embedded micromotor actuation [49]. The distal tip is articulated with four distal joints that can be independently controlled, permitting eight degrees of freedom. Position control of the motorized joints allows precise motions of the robot for accurate dissection and tissue handling.

An on-board camera and light source are housed within the flexible shaft, and two 3-mm working channels allow flexible instruments to be used interchangeably. The snake is guided by the operator with an ergonomic hand-held interface. This allows realignment of the motor-visual axes of the operator, allowing them to remain oriented during the procedure. Preliminary tubal ligation studies [50] and feasibility studies for robotic gastric endoscopic submucosal dissection and peroral endoscopic myotomy are being carried out.

\section{Engineering problems, developments, and the future}

$\nabla$

The evolution of a multitasking flexible platform for NOTES and ELS is still in flux. Current surgical and endoscopic platforms and their instrumentation are characterized by technical limitations that affect their performance and large-scale application.

A technical limitation of a number of platforms is inadequate triangulation of instruments. Balloons may be useful in the esophagus but are unlikely to be of use in a large cavity, such as the stomach. Several solutions have been considered to address this issue, including telescopic camera holders, angled vision endoscopes, and instruments provided with elbows able to align the axis.

Potential solutions to tight endoluminal workspaces are compact wristed bimanual instruments, which may increase instrument dexterity; however, the ideal force required at the instrument tip is about $9 \mathrm{~N}$ to enable robust tissue manipulation . Reaching these force requirements is challenging, and it is estimated that endoscopic instruments apply only $20 \%$ of the force that laparoscopic tools are able to apply [51].

Although the basic design of the endoscope has changed little since it was developed, a paradigm shift in flexible endoscopy and a surge of new technologies may lead to a new generation of interventional multitasking endoscopes, allowing the firm integration of NOTES and ELS into routine practice. Miniature robots, micro-robots, wireless technologies, soft robotics, and magnets are among the emerging technologies that may impact the future of NOTES and ELS. Could this in turn pave the way for a new generation of operators - hybrid gastroenterologists and surgeons?

\section{Competing interests: None}

\section{References}

1 Bozzini P. Light conductor, an invention for examining internal parts and diseases, together with illustrations. J Pract Med Surg 1806; 24 : $107-124$

2 Meining A, Spaun G, Fernández-Esparrach $G$ et al. NOTES in Europe: summary of the working group reports of the 2012 EURO-NOTES meeting. Endoscopy 2013; 45: 214-217

3 Rattner D, Kalloo A. SAGES/ASGE Working Group. ASGE/SAGES working group on natural orifice translumenal endoscopic surgery. October 2005. Surg Endosc 2006; 20: 329-333

4 Cosentino F, Tumino E, Passoni GR et al. Functional evaluation of the endotics system, a new disposable self-propelled robotic colonoscope: in vitro tests and clinical trial. Int J Artif Organs 2009; 32: 517-527

5 Valdastri P, Ciuti G, Verbeni A et al. Magnetic air capsule robotic system: proof of concept of a novel approach for painless colonoscopy. Surg Endosc 2012; 26: 1238 - 1246

6 Ciuti G, Valdastri P, Menciassi A et al. Robotic magnetic steering and locomotion of capsule endoscope for diagnostic and surgical endoluminal procedures. Robotica 2010; 28: 199-207

7 Bessler M, Stevens P, Milone L et al. Transvaginal laparoscopic cholecystectomy: laparoscopically assisted. Surg Endosc 2008; 22: 1715-1716

8 Mintz Y, Horgan S, Cullen J et al. NOTES: the hybrid technique. J Laparoendosc Adv Surg Tech 2007; 17: 402 - 406

9 Spaun GO, Zheng B, Swanström LL. A multitasking platform for natural orifice translumenal endoscopic surgery (NOTES): a bench top comparison of a new device for flexible endoscopic surgery and a standard dual-channel endoscope. Surg Endosc 2009; 23: 2720-2727 
10 Fuchs $K H$, Breithaupt $W$. Transgastric small bowel resection with the new multitasking platform EndoSamurai ${ }^{\mathrm{TM}}$ for natural orifice transluminal endoscopic surgery. Surg Endosc 2012; 26: 2281 - 2287

11 Dallemagne $B$, Marescaux J. The ANUBIS project. Minim Invasive Ther Allied Technol 2010; 19: 257-261

12 Allemann P, Perretta S, Asakuma $M$ et al. Multimedia manuscript. NOTES retroperitoneal transvaginal distal pancreatectomy. Surg Endosc 2009; 23: $882-883$

13 Leroy J, Cahill RA, Perretta $S$ et al. Natural orifice translumenal endoscopic surgery (NOTES) applied totally to sigmoidectomy: an original technique with survival in a porcine model. Surg Endosc 2009; 23 . $24-30$

14 Dallemagne B, Perretta S, Allemann $P$ et al. Transgastric hybrid cholecystectomy. Br J Surg 2009; 96: $1162-1166$

15 Perretta $S$, Dallemagne B, Coumaros $D$ et al. Natural orifice transluminal endoscopic surgery: transgastric cholecystectomy in a survival porcine model. Surg Endosc 2008; 22: 1126-1130

16 Perretta $S$, Dallemagne B, Barry $B$ et al. The ANUBISCOPE( $\left.{ }^{(}\right)$flexible platform ready for prime time: description of the first clinical case. Surg Endosc 2013; 23: 2630

17 Neuhaus H, Costamagna G, Devière J et al. Endoscopic submucosal dissection (ESD) of early neoplastic gastric lesions using a new doublechannel endoscope (the "R-scope"). Endoscopy 2006; 38: 1016-1023

18 Ishii $K$, Tajiri H, Fujisaki J et al. The effectiveness of a new multibending scope for endoscopic mucosal resection. Endoscopy 2004; 36: 294e7

19 Sumiyama K, Kaise M, Nakayoshi T et al. Combined used of a magnifying endoscope with a narrow band imaging system and a multibending endoscope for en bloc EMR of early stage gastric cancer. Gastrointest Endosc 2004; 60: 79-84

20 Sumiyama K, Gostout CJ, Rajan E et al. Transgastric cholecystectomy: transgastric accessibility to the gallbladder improved with the SEMF method and a novel multibending therapeutic endoscope. Gastrointest Endosc 2007; 65: 1028 - 1034

21 Ryou M, Fong DG, Pai RD et al. Dual-port distal pancreatectomy using a prototype endoscope and endoscopic stapler: a natural orifice transluminal endoscopic surgery (NOTES) survival study in a porcine model. Endoscopy 2007; 39: 881 - 887

22 Lee SH, Gromski MA, Derevianko A et al. Efficacy of a prototype endoscope with two deflecting working channels for endoscopic submucosal dissection: a prospective, comparative, ex vivo study. Gastrointest Endosc 2010; 72: 155-160

23 Moyer MT, Haluck RS, Gopal J et al. Transgastric organ resection solely with the prototype R-scope and the self-approximating transluminal access technique. Gastrointest Endosc 2010; 72: 170-176

24 Astudillo JA, Sporn E, Bachman S et al. Transgastric cholecystectomy using a prototype endoscope with 2 deflecting working channels (with video). Gastrointest Endosc 2009; 69: 297-302

25 Swain $P$, Ewers $R$, Peh $R$ et al. New measurement methods and a randomized comparison of force transmission using flexible endoscopes and instruments before and after the application of Shapelock technology. Gastrointest Endosc 2005; 61: AB241

26 Swanstrom $L L$, Swain P, Denk P. Development and validation of a new generation of flexible endoscope for NOTES. Surg Innov 2009; 16: $104 \mathrm{e} 10$

27 Horgan S, Thompson K, Talamini $M$ et al. Clinical experience with a multifunctional, flexible surgery system for endolumenal, singleport, and NOTES procedures. Surg Endosc 2011; 25: 586- 592

28 Horgan S, Jacobsen G, Weiss GD et al. Incisionless revision of post-Rouxen-Y bypass stomal and pouch dilation: multicentre registry results. Surg Obes Relat Dis 2010; 6: 290-295

29 Pai RD, Fong DG, Bundga ME et al. Transcolonic endoscopic cholecystectomy: a NOTES survival study in a porcine model (with video). Gastrointest Endosc 2006; 64: 428

30 Swain $P$, Rothe $C$, Bergstrom $M$ et al. Development and testing of a new platform for retroflexed flexible transgastric surgery: cholecystectomy, fundoplication, gastric restriction and diaphragmatic repair. Gastrointest Endosc 2006; 63: 725
31 Bardaro SJ, Swanstrom LL. Development of advanced endoscopes for natural orifice translumenal endoscopic surgery (NOTES). Minim Invasive Ther Allied Technol 2006; 15: 378 - 383

32 Thompson CC, Ryou M, Soper NJ et al. Evaluation of a manually driven, multitasking platform for complex endoluminal and natural orifice translumenal endoscopic surgery applications (with video). Gastrointest Endosc 2009; 70: 121 - 125

33 Potter K, Swanstrom L. Natural orifice surgery (NOTES) and biliary disease, is there a role? J Hepatobiliary Pancreatic Surg 2009; 16: 261 265

34 Spaun GO, Zheng B, Martinec DV et al. Bimanual coordination in natural orifice transluminal endoscopic surgery: comparing the conventional dual-channel endoscope, the R-Scope, and a novel direct-drive system. Gastrointest Endosc 2009; 69: 39-45

35 Simaan $N, X u K$, Wei Wet al. Design and integration of a telerobotic system for minimally invasive surgery of the throat. Int J Rob Res 2009; 28: $1134-1153$

36 Shammas $E$, Wolf $A$, Choset $H$. Three degrees-of-freedom joint for spatial hyper-redundant robots. Mechanism Machine Theory 2006; 41 : $170-190$

37 Petroni G, Niccolini M, Caccavaro S et al. A novel robotic system for single-port laparoscopic surgery: preliminary experience. Surg Endosc 2013; 27: 1932 - 1937

38 Eickhoff A, Jakobs R, Kamal A et al. In vitro evaluation of forces exerted by a new computer-assisted colonoscope (the NeoGuide Endoscopy System). Endoscopy 2006; 38: 1224-1229

39 Striegel J, Jakobs R, Van Dam J et al. Determining scope position during colonoscopy without use of ionizing radiation or magnetic imaging: the enhanced mapping ability of the NeoGuide Endoscopy System. Surg Endosc 2011; 25: 636-640

40 Eickhoff A, van Dam J, Jakobs $R$ et al. Computer-assisted colonoscopy (the NeoGuide Endoscopy System): results of the first human clinical trial ("PACE study"). Am J Gastroenterol 2007; 102: 261 - 266

41 Bardou B, Nageotte F, Zanne P et al. Design of a telemanipulated system for transluminal surgery. Conf Proc IEEE Eng Med Biol Soc 2009: $5577-5582$

42 Abbott DJ, Becke C, Rothstein RI et al. Design of an endoluminal NOTES robotic system. IEEE/RSJ International Conference on Intelligent Robots and Systems 2007: 410-416

43 Phee SJ, Low SC, Sun ZL et al. Robotic system for no-scar gastrointestinal surgery. Int J Med Robot 2008; 4: 15-22

44 Phee SJ, Low SC, Huynh VA et al. Master and slave transluminal endoscopic robot (MASTER) for natural orifice transluminal endoscopic surgery (NOTES). Conf Proc IEEE Eng Med Biol Soc 2009: 1192-1195

45 Sun Z, Ang RY, Lim EW et al. Enhancement of a master-slave robotic system for natural orifice transluminal endoscopic surgery. Ann Acad Med Singapore 2011; 40: $223-230$

46 Phee $S$, Ho K, Lomanto $D$ et al. Natural orifice transgastric endoscopic wedge hepatic resection in an experimental model using an intuitively controlled master and slave transluminal endoscopic robot (MASTER). Surg Endosc 2010; 24: 2293 - 2298

47 Wang Z, Phee SJ, Lomanto D et al. Endoscopic submucosal dissection of gastric lesions by using a master and slave transluminal endoscopic robot: an animal survival study. Endoscopy 2012; 44: 690-694

48 Phee SJ, Reddy N, Chiu PW et al. Robot-assisted endoscopic submucosal dissection is effective in treating patients with early-stage gastric neoplasia. Clin Gastroenterol Hepatol 2012; 10: 1117-1121

49 Ho $K Y$, Phee SJ, So BYJ et al. Robotic manipulator for natural orifice transluminal endoscopic surgery. Gastrointest Endosc 2007; 65: AB110

50 Shang J, Noonan DP, Payne $C$ et al. An articulated universal joint based flexible access robot for minimally invasive surgery. IEEE 2011: 1147 1152

51 Clark J, Sodergren M, Noonan DP et al. A novel articulated robotic laparoscope for single incision and natural orifice surgical applications: preliminary usability trials in a live porcine model. 2010 Annual Meeting of the Society of American Gastrointestinal and Endoscopic Surgeons. Surg Endosc 2010; 24: S690 